\title{
REKAYASA NILAI PADA PROYEK PEMBANGUNAN GEDUNG KANTOR BPS PROVINSI SULAWESI TENGGARA
}

\author{
Surya Baskara \\ Universitas Muhammadiyah Kendari \\ Jurusan Arsitektur, Fakultas Teknik Universitas Muhammadiyah Kendari \\ Email: uyabaskara@gmail.com
}

\begin{abstract}
Abstrak
Dalam perencanaan pembangunan suatu proyek umumnya tidak dipertimbangkan alternatif yang dapat mengurangi biaya-biaya yang tidak diperlukan. Pekerjaan pembesian secara manual pada pekerjaan balok dan kolom serta pekerjaan pelat konvensional pada Proyek Pembangunan Gedung Kantor Badan Pusat Statistik (BPS) Provinsi Sulawesi Tenggara akan dicoba alternatif lain dengan melakukan analisa rekayasa nilai. Dengan analisa tersebut diharapkan dapat menguragi biaya-biaya yang tidak diperlukan sehingga dapat mengoptimalkan biaya dan waktu tanpa mengurangi mutu yang diinginkan. Analisa rekayasa nilai ini menggunakan tahap-tahap rencana kerja rekayasa nilai yaitu : tahap informasi, tahap spekulasi, tahap analisa dan tahap penyajian. Untuk menilai alternatif-alternatif pekerjaan dengan analisa rekayasa nilai ini, digunakan kriteria-kriteria penilaian beserta bobot penilaiannya. Kriteria-kriteria yang digunakan terdiri dari biaya, waktu, hasil akhir dan pelaksanaan. Alternatif usulan yang memungkinkan untuk diterapkan dalam proyek tersebut diatas adalah pekerjaan pembesian manual dengan mesin dan pekerjaan pelat halfslab tulangan polos dan pelat halfslab tulangan wiremesh. Berdasarkan analisa yang dilakukan, diperoleh alternatif yang dapat memenuhi fungsi dengan penghematan biaya yang paling besar dibandingkan dengan alternatif-alternatif lainnya, yaitu pelaksanaan pekerjaan pembesian manual dengan mesin dan pelaksanaan pekerjaan pelat halfslab tulangan wiremesh. Dengan penghematan potensial sebesar Rp. 479.328 .386 atau serta untuk waktu pelaksanaan dapat dihemat selama 11 hari.
\end{abstract}

Kata Kunci: rekayasa nilai, alternatif, penghematan

\begin{abstract}
Abstact
In the development planning of a project it is generally not considered an alternative that can reduce unnecessary costs. The manual cleaning work on beam and column work and conventional plate work on the Southeast Sulawesi Provincial Central Bureau of Statistics (BPS) Construction Project will be tried other alternatives by conducting value engineering analysis. With this analysis it is expected to reduce costs that are not needed so as to optimize costs and time without reducing the desired quality. This value engineering analysis uses the stages of
\end{abstract}


value engineering work plan, namely: the information stage, the speculation stage, the analysis phase and the presentation stage. To assess work alternatives with this value engineering analysis, the assessment criteria are used along with the weight of the assessment. The criteria used consist of costs, time, final results and implementation. The alternative proposals that are possible to be applied in the project above are manual machining work and the work of plain reinforcement half-plate plates and wiremesh reinforcement half-plate plates. Based on the analysis carried out, obtained an alternative that can fulfill the function with the greatest cost savings compared to other alternatives, namely the implementation of manual maintenance work with machines and the implementation of wiremesh reinforcement half-plate work. With a potential savings of Rp. 479,328,386 or for the execution time can be saved for 11 days

Keywords: value engineering, alternatives, savings

\subsection{Pendahuluan}

\section{PENDAhULUAN}

Perkembangan rekayasa Teknik Sipil pada saat ini mengalami kemajuan yang sangat pesat serta menuntut perencanaan suatu proyek untuk mengoptimalkan biaya, mutu, dan waktu karena adanya keterbatasan sumber daya berupa material, dana, maupun tenaga kerja.

Seringkali pada tahap pelaksanaan, perencana kurang memperhatikan dan kurang teliti dalam memilih metode pelaksanaan yang akan digunakan sehingga anggaran biaya biasanya langsung menggunakan metode pelaksanaan tanpa mempertimbangkan alternatifalternatif yang lain.

Pada Gedung Kantor Badan Pusat Statistik (BPS) Provinsi Sulawesi Tenggara ini masih menggunakan plat konvensional serta pembesian pada balok dan kolom secara manual. Hal ini yang membuat proyek tersebut berlangsung relatif lama. Sedangkan tuntutan untuk segera mendapatkan Gedung Kantor yang baru sangat besar demi kelancaran dan kenyamanan pegawai dalam melaksanakan pekerjaannya. Oleh karena itu perlu diadakan Rekayasa Nilai..

Pemilihan item-item pekerjaan tersebut dikarenakan item pekerjaan tersebut merupakan item pekerjaan yang vital dalam membangun sebuah gedung. Selain itu juga karena item pekerjaan tersebut sangat membutuhkan biaya yang banyak serta waktu yang relatif lama.

\subsection{Rumusan Masalah}

1. Bagaimana pengaruh metode pelaksanaan terhadap biaya dan waktu proyek ?

2. Berapa penghematan biaya dan waktu yang diperoleh dari penerapan rekayasa nilai pada pekerjaan struktur? 
1.3. Tujuan Penelitian

1. Mengetahui pengaruh metode pelaksanaan terhadap waktu dan biaya proyek.

2. Mengetahui penghematan biaya dan waktu yang diperoleh dari penerapan rekayasa nilai pada pekerjaan struktur.

\subsection{Batasan Masalah}

1. Obyek analisis adalah Proyek Pembangunan Gedung Kantor Badan Pusat Statistik (BPS) Provinsi Sulawesi Tenggara.

2. Analisa rekayasa nilai dilakukan pada metode pelaksanaan pekerjaan struktural.

3. Sub item pekerjaan struktur yang akan dianalisa adalah metode pelaksanaan pekerjaan pembesian pada kolom dan balok dan metode pelaksanaan pekerjaan plat.

1.5. Manfaat Penelitian

Manfaat dari penelitian ini adalah mengurangi biaya-biaya yang tidak perlu yang disebabkan oleh tidak tepatnya pemilihan metode pelaksanaan sehingga dapat mengoptimalkan biaya dan waktu tanpa mengurangi mutu yang diinginkan.

\subsection{Landasan Teori}

Rekayasa nilai merupakan suatu teknik dalam perancangan produk. Secara umum, rekyasa nilai bertujuan untuk mengidentifikasi dan menghilangkan biaya-biaya yang tidak perlu, tanpa mengorbankan kualitas produk.

\section{a. Tahap Informasi}

\section{METODE PENELITIAN}

Tahap informasi dari proses rekayasa nilai meliputi : merumuskan masalah, mengumpulkan fakta, mengenal obyek (produk) dengan mengkaji fungsi, dan mencatat biaya.

\section{b. Tahap Spekulasi}

Pada tahap ini kemungkinan lain dianalisa dengan menanyakan apakah ada alternatif lain yang dapat memenuhi fungsi atau kegunaan yang sama. Pada tahap ini pula mulai diperlukan kreatifitaspenggunaan imajinasi dan pemunculan ide-ide baru yang dimaksudkan untuk diimplementasikan.

\section{c. Tahap Analisa}

Pada tahap ini ide-ide yang dimunculkan ditahap sebelumnya dianalisa dan dikritik. 


\section{d. Tahap Penyajian}

Tahap ini merupakan tahap akhir proses Rekayasa Nilai, yang berisi penyajian kesimpulan hasil rekayasa nilai kepada yang berkepentingan. Laporan hanya menyajikan fakta informasi untuk mendukung argumentasi. Semua aspek teknik dan biaya desain semula dibandingkan hasil rekayasa nilai dipaparkan dengan jelas.

\section{PEMBAHASAN}

Nama Proyek $\quad$ : Proyek Pembangunan Gedung Kantor Badan Pusat Statistik (BPS) Provinsi Sulawesi Tenggara

Lokasi Proyek $\quad$ : J1. Boulevard No. 1 Kendari Sulawesi Tenggara

Nama Pemilik : : Badan Pusat Stastik (BPS) Provinsi Sulawesi Tenggara

Kontraktor Pelaksana : PT. Candra Adyalaksana

Konsultan Pengawas : PT. Kaison Konsultan

Nilai Proyek $\quad$ : Rp. 10.164.502.648,32

Tabel 1 Breakdown Biaya

\begin{tabular}{|c|c|c|c|c|c|}
\hline \multirow{2}{*}{ No } & \multirow{2}{*}{ Item Pekerjaan } & Biaya & $\begin{array}{c}\text { Biaya } \\
\text { Komulatif }\end{array}$ & $\begin{array}{c}\text { Prosentase } \\
\text { Biaya }\end{array}$ & \multirow{2}{*}{$\begin{array}{c}\text { Prosentase } \\
\text { Biaya } \\
\text { Komulatif } \\
(\%)\end{array}$} \\
\hline & & $(\mathrm{Rp})$ & (Rp) & $(\%)$ & \\
\hline 1 & Pekerjaan Persiapan & $110.480 .200,00$ & $110.480 .200,00$ & 1,09 & 1,09 \\
\hline 2 & Pekerjaan Struktur & $3.232 .095 .671,76$ & 3.342.575.871,76 & 31,80 & 32,88 \\
\hline 3 & Pekerjaan Arsitektur & 3.727.054.771,09 & 7.069.630.642,86 & 36,67 & 69,55 \\
\hline 4 & Pekerjaan Mekanik \& Elektronik & $2.520 .435 .750,00$ & $9.590 .066 .392,86$ & 24,80 & 94,35 \\
\hline 5 & Pekerjaan Plumbing \& Pemadam Kebakaran & $558.686 .255,47$ & $10.148 .752 .648,32$ & 5,50 & 99,85 \\
\hline 6 & Pekerjaan Anti Rayap & $15.750 .000,00$ & $10.164 .502 .648,32$ & 0,15 & 100 \\
\hline & Jumlah Biaya & \multicolumn{4}{|c|}{$10.164 .502 .648,32$} \\
\hline
\end{tabular}

\section{e. Tahap Informasi}

Tahap pertama dalam analisa rekayasa nilai adalah mengidentifikasi pekerjaan yang akan ditinjau dengan mengumpulkan informasi dan data-data teknis sebanyak mungkin yang mendukung. Informasi pada pekerjaan struktur dapat dilihat dalam Tabel 2. 
Tabel 2 Data Teknik Proyek

\begin{tabular}{|c|c|l|}
\hline No & Pekerjaan & \multicolumn{1}{|c|}{ Data Teknis Proyek } \\
\hline \multirow{2}{*}{1} & \multirow{2}{*}{ Plat } & Pembesian Manual \\
\cline { 3 - 3 } & & Biaya Rp. 1.018.843.950 \\
\cline { 3 - 3 } 2 & \multirow{2}{*}{ Balok dan Kolom } & Petode Konvensional \\
\cline { 3 - 3 } & & Biaya Rp. 1.245.863.977 \\
\hline
\end{tabular}

Total biaya pekerjaan yang akan dilakukan analisa rekayasa nilai sebesar Rp. 2.264.707.927.

\section{f. Tahap Spekulasi}

Pada tahapan ini dilakukan penggalian ide alternatif desain dari elemen pekerjaan yang telah dianalisa pada tahap analisa fungsi.

Tabel 3 Tahap Spekulasi

\begin{tabular}{|c|c|l|}
\hline No & Item Pekerjaan Awal & \multicolumn{1}{|c|}{ Item Pekerjaan Usulan } \\
\hline 1 & Pembesian manual konvensional & Pembesian manual dengan mesin \\
\hline \multirow{2}{*}{2} & Pekerjaan plat konvensional & Pekerjaan plat halfslab tulangan polos \\
\cline { 3 - 3 } & & Pekerjaan plat halfslab wiremesh \\
\hline
\end{tabular}

\section{g. Tahap Analisa}

Berdasarkan perhitungan maka waktu total yang dibutuhkan untuk melaksanakan seluruh pekerjaan pembesian,bekisting dan pelat dapat dilihat pada tabel-tabel berikut

Tabel 4 Waktu Total Pekerjaan Pembesian

\begin{tabular}{|c|c|r|c|}
\hline No & Jenis Pekerjaan & Volume (Kg) & Waktu (Hari) \\
\hline 1 & Pembesian manual konvensional & $88.000,20$ & 88 \\
\hline 2 & Pembesian manual dengan mesin & $88.000,20$ & 83 \\
\hline
\end{tabular}

Tabel 5 Biaya Total Pekerjaan Pembesian

\begin{tabular}{|c|c|r|c|}
\hline No & Jenis Pekerjaan & Volume $(\mathrm{Kg})$ & Biaya $(\mathrm{Rp})$ \\
\hline 1 & Pembesian manual konvensional & $88.000,20$ & 732.087 .667 \\
\hline 2 & Pembesian manual dengan mesin & $88.000,20$ & 560.973 .200 \\
\hline
\end{tabular}


Tabel 6 Waktu Total Pekerjaan Plat

\begin{tabular}{|c|l|r|c|}
\hline No & \multicolumn{1}{|c|}{ Jenis Pekerjaan } & Volume $(\mathrm{Kg})$ & Waktu (Hari) \\
\hline 1 & Pekerjaan plat konvensional & 307,6 & 13 \\
\hline 2 & Pekerjaan plat halfslab tulangan polos & 307,6 & 8 \\
\hline 3 & Pekerjaan plat halfslab wiremesh & 307,6 & 7 \\
\hline
\end{tabular}

Tabel 7 Biaya Total Pekerjaan Plat

\begin{tabular}{|c|l|r|r|}
\hline No & \multicolumn{1}{|c|}{ Jenis Pekerjaan } & Volume $(\mathrm{Kg})$ & Biaya $(\mathrm{Rp})$ \\
\hline 1 & Pekerjaan plat konvensional & 307,6 & 1.018 .843 .950 \\
\hline 2 & Pekerjaan plat halfslab tulangan polos & 307,6 & 792.373 .073 \\
\hline 3 & Pekerjaan plat halfslab wiremesh & 307,6 & 710.630 .031 \\
\hline
\end{tabular}

\section{h. Analisa Pengambilan Keputusan}

Analisa pemilihan alternatif multikriteria dilakukan dengan menggunakan metode matriks yang dilakukan dengan menggunakan metode matriks zero one (0-1). Pembobotan kriteria menggunakan matriks tersebut dengan cara membandingkan kriteria yang satu dengan kriteria yang lain. Kriteria yang lebih diunggulkan diberi nilai 1, kriteria yang sama tidak diberi nilai sedangkan yang kurang diunggulkn diberi nilai 0. Pembobotan kriteria pekerjaan pembesian dan pelat ditunjukkan pada tabel 8 dan tabel 9. Adapun kriteria yang digunakan dalam analisa ini adalah :

Tabel 8 Matriks Evaluasi Pekerjaan Pembesian

\begin{tabular}{|c|l|c|c|c|c|c|c|c|}
\hline No & \multicolumn{1}{|c|}{ Kriteria } & A & B & C & D & Jumlah & Ranking & Bobot \\
\hline A & Biaya & - & 1 & 1 & 1 & 3 & 1 & 5 \\
\hline B & Waktu & 0 & - & 1 & 1 & 2 & 2 & 4 \\
\hline C & Pelaksanaan & 0 & 0 & - & 1 & 1 & 3 & 3 \\
\hline D & Hasil Akhir & 0 & 0 & 0 & - & 0 & 4 & 2 \\
\hline
\end{tabular}

Tabel 9 Matriks Evaluasi Pekerjaan Pelat

\begin{tabular}{|c|l|c|c|c|c|c|c|c|}
\hline No & Kriteria & A & B & C & D & Jumlah & Ranking & Bobot \\
\hline A & Waktu & - & 1 & 1 & 1 & 3 & 1 & 5 \\
\hline B & Biaya & 0 & - & 1 & 1 & 2 & 2 & 4 \\
\hline C & Pelaksanaan & 0 & 0 & - & 1 & 1 & 3 & 3 \\
\hline D & Hasil Akhir & 0 & 0 & 0 & - & 0 & 4 & 2 \\
\hline
\end{tabular}

Setelah dilakukan analisis untuk menentukan urutan kriteria, maka langkah selanjutnya adalah memberikan bobot pada masing-masing kriteria dengan angka numerik 1 sampai dengan 4, nilai 1 menyatakan nilai terendah / merugikan sedangkan nilai 4 menyatakan nilai tertinggi / 
menguntungkan. Bobot kriteria untuk pekerjaan pembesian dan pelat ditunjukkan pada tabel 10 dan tabel 11. Rekapitulasi kriteria pekerjaan pembesian dan pelat ditunjukkan pada tabel 12 dan tabel 13 .

Tabel 10 Kriteria Pekerjaan Pembesian

\begin{tabular}{|c|c|c|c|}
\hline No & Parameter & Standar Penilaian & Bobot \\
\hline \multirow{4}{*}{1} & \multirow{4}{*}{ Biaya (Rp) } & $550.000 .000-600.000 .000$ & 4 \\
\hline & & $600.000 .000-650.000 .000$ & 3 \\
\hline & & $650.000 .000-700.000 .000$ & 2 \\
\hline & & $700.000 .000-750.000 .000$ & 1 \\
\hline \multirow{4}{*}{2} & \multirow{4}{*}{ Waktu (Hari) } & $82-83$ & 4 \\
\hline & & $84-85$ & 3 \\
\hline & & $86-87$ & 2 \\
\hline & & $88-89$ & 1 \\
\hline \multirow{4}{*}{3} & \multirow{4}{*}{ Pelaksanaan } & Sangat Mudah & 4 \\
\hline & & Mudah & 3 \\
\hline & & Sulit & 2 \\
\hline & & Sangat Sulit & 1 \\
\hline \multirow{4}{*}{4} & \multirow{4}{*}{ Hasil Akhir } & Sangat Baik & 4 \\
\hline & & Baik & 3 \\
\hline & & Cukup Baik & 2 \\
\hline & & Tidak Baik & 1 \\
\hline
\end{tabular}

Tabel 11 Kritera Pekerjaan Plat 


\begin{tabular}{|c|c|c|c|}
\hline No & Parameter & Standar Penilaian & Bobot \\
\hline \multirow{4}{*}{1} & \multirow{4}{*}{ Waktu (Hari) } & $6-7$ & 4 \\
\hline & & $8-9$ & 3 \\
\hline & & $10-11$ & 2 \\
\hline & & $12-13$ & 1 \\
\hline \multirow{4}{*}{2} & \multirow{4}{*}{ Biaya (Rp) } & $700.000 .000-800.000 .000$ & 4 \\
\hline & & $800.000 .000-900.000 .000$ & 3 \\
\hline & & $900.000 .000-1.000 .000 .000$ & 2 \\
\hline & & $1.000 .000 .000-1.100 .00 .000$ & 1 \\
\hline \multirow{4}{*}{3} & \multirow{4}{*}{ Pelaksanaan } & Sangat Mudah & 4 \\
\hline & & Mudah & 3 \\
\hline & & Sulit & 2 \\
\hline & & Sangat Sulit & 1 \\
\hline \multirow{4}{*}{4} & \multirow{4}{*}{ Hasil Akhir } & Sangat Baik & 4 \\
\hline & & Baik & 3 \\
\hline & & Cukup Baik & 2 \\
\hline & & Tidak Baik & 1 \\
\hline
\end{tabular}

Tabel 12 Rekapitulasi Pekerjaan Pembesian

\begin{tabular}{|c|c|c|c|c|}
\hline No & Jenis Pekerjaan & Kriteria & Keterangan & Bobot \\
\hline \multirow{4}{*}{1} & \multirow{4}{*}{ Manual Konvensinal } & Waktu (Hari) & 88 & 1 \\
\cline { 3 - 5 } & & Biaya (Rp) & 732.087 .667 & 1 \\
\cline { 3 - 5 } & & Pelaksanaan & Sulit & 2 \\
\cline { 3 - 5 } 2 & Hasil Akhir & Baik & 3 \\
\hline \multirow{4}{*}{} & \multirow{4}{*}{ Manual Dengan Mesin } & Waktu (Hari) & 83 & 4 \\
\cline { 3 - 5 } & & Biaya (Rp) & 560.973 .200 & 4 \\
\cline { 3 - 5 } & Pelaksanaan & Mudah & 3 \\
\cline { 3 - 5 } & Hasil Akhir & Sangat Baik & 4 \\
\hline
\end{tabular}

Tabel 13 Rekapitulasi Pekerjaan Pelat 


\begin{tabular}{|c|c|c|c|c|}
\hline No & Jenis Pekerjaan & Kriteria & Keterangan & Bobot \\
\hline \multirow{4}{*}{1} & \multirow{4}{*}{ Konvensional } & Waktu (Hari) & 13 & 1 \\
\hline & & Biaya (Rp) & 1.018 .843 .950 & 1 \\
\hline & & Pelaksanaan & Mudah & 3 \\
\hline & & Hasil Akhir & Baik & 3 \\
\hline \multirow{4}{*}{2} & \multirow{4}{*}{ Halfslab tulangan polos } & Waktu (Hari) & 8 & 3 \\
\hline & & Biaya (Rp) & 710.630 .031 & 4 \\
\hline & & Pelaksanaan & Sangat Mudah & 4 \\
\hline & & Hasil Akhir & Sangat Baik & 4 \\
\hline \multirow{4}{*}{3} & \multirow{4}{*}{ Halfslab wiremesh } & Waktu (Hari) & 7 & 4 \\
\hline & & Biaya (Rp) & 792.373 .073 & 4 \\
\hline & & Pelaksanaan & Sangat Mudah & 4 \\
\hline & & Hasil Akhir & Sangat Baik & 4 \\
\hline
\end{tabular}

Setelah mengetahui bobot atas sejumlah parameter penguji untuk masing-masing pekerjaan maka langkah terakhir pada tahap analisis adalah menentukan urutan kelayakan atas sejumlah alternatif yang didapat pada tahap kreatif dengan menggunakan analisis matriks yang bertujuan mendapatkan urutan penghematan potensial dari alternatif yang diusulkan. Dengan demikian dapat diputuskan alternatif penghematan potensial yang paling maksimum. Analisa penilaian berpasangan alternatif untuk pekerjaan pembesian dan pelat ditunjukkan pada tabel 14 dan tabel 15.

Tabel 14 Analisa Penilaian Berpasangan Alternatif Pekerjaan Pembesian

\begin{tabular}{|c|c|c|c|c|c|c|}
\hline \multirow{2}{*}{ No } & \multirow{2}{*}{ Kriteria } & \multirow{2}{*}{$\begin{array}{c}\text { Bobot } \\
\text { Kriteria }\end{array}$} & \multicolumn{2}{c|}{ Manual } & \multicolumn{2}{c|}{ Manual } \\
\cline { 4 - 7 } & & & \multicolumn{2}{c|}{ Konvensional } & \multicolumn{2}{c|}{ Dengan Mesin } \\
\cline { 4 - 7 } & & Bobot & Hasil & Bobot & Hasil \\
\hline 1 & Biaya & 5 & 1 & 5 & 4 & 20 \\
\hline 2 & Waktu & 4 & 1 & 4 & 4 & 16 \\
\hline 3 & Pelaksanaan & 3 & 2 & 6 & 3 & 9 \\
\hline 4 & Hasil Akhir & 2 & 3 & 6 & 4 & 8 \\
\hline \multicolumn{3}{|c|}{ Total Hasil } & \multicolumn{2}{|c|}{25} & \multicolumn{2}{|c|}{53} \\
\hline \multicolumn{3}{|c|}{ Rangking } & \multicolumn{2}{c|}{2} & \multicolumn{2}{c|}{1} \\
\hline
\end{tabular}

Tabel 15 Analisa Penilaian Berpasangan Alternatif Pekerjaan Pelat 


\begin{tabular}{|c|c|c|c|c|c|c|c|c|}
\hline \multirow[t]{2}{*}{ No } & \multirow[t]{2}{*}{ Kriteria } & \multirow[t]{2}{*}{$\begin{array}{l}\text { Bobot } \\
\text { Kriteria }\end{array}$} & \multicolumn{2}{|c|}{ Konvensional } & \multicolumn{2}{|c|}{$\begin{array}{c}\text { Halfslab } \\
\text { Tulangan Polos }\end{array}$} & \multicolumn{2}{|c|}{$\begin{array}{c}\text { Halfslab } \\
\text { Wiremesh }\end{array}$} \\
\hline & & & Bobot & Hasil & Bobot & Hasil & Bobot & Hasil \\
\hline 1 & Waktu & 5 & 1 & 5 & 3 & 15 & 4 & 20 \\
\hline 2 & Biaya & 4 & 1 & 4 & 4 & 16 & 4 & 16 \\
\hline 3 & Pelaksanaan & 3 & 3 & 9 & 4 & 12 & 4 & 12 \\
\hline 4 & Hasil Akhir & 2 & 3 & 6 & 4 & 8 & 4 & 8 \\
\hline \multicolumn{3}{|c|}{ Total Hasil } & \multicolumn{2}{|c|}{24} & \multicolumn{2}{|c|}{51} & \multicolumn{2}{|c|}{56} \\
\hline \multicolumn{3}{|c|}{ Rangking } & \multicolumn{2}{|c|}{3} & \multicolumn{2}{|c|}{2} & \multicolumn{2}{|c|}{1} \\
\hline
\end{tabular}

\section{i. Tahap Penyajian}

Setelah dilakukan tahapan analisa pemilihan alternatif dan ditentukan alternatif terbaik, maka tahap terakhir dalam melakukan rekayasa nilai adalah memberikan rekomendasi dalam bentuk tabel atas hasil studi yang telah dilakukan.

Tabel 16 Tahap Penyajian

\begin{tabular}{|c|c|c|c|c|}
\hline No & Pekerjaan & Rencana Awal & Rencana Alternatif & Keuntungan \\
\hline \multirow{5}{*}{1} & \multirow{5}{*}{ Pembesian } & \multirow{5}{*}{ Manual konvensional } & \multirow{5}{*}{ Manual dengan mesin } & - Biaya lebih murah \\
\hline & & & & (Rp. 171.114.467) \\
\hline & & & & - Waktu lebih cepat \\
\hline & & & & (5 hari) \\
\hline & & & & - Pelaksanaan lebih mudah \\
\hline \multirow{5}{*}{2} & \multirow{5}{*}{ Plat } & \multirow{5}{*}{ Plat konvensional } & \multirow{5}{*}{ Plat halfslab wiremesh } & - Biaya lebih murah \\
\hline & & & & (Rp. 308.213.919) \\
\hline & & & & - Waktu lebih cepat \\
\hline & & & & (6 hari) \\
\hline & & & & - Pelaksanaan lebih mudah \\
\hline
\end{tabular}

\section{KESIMPULAN}

1. Metode pelaksanaan berpengaruh terhadap biaya, waktu, hasil akhir dan pelaksanaan proyek yang berbeda - beda pada masing - masing alternatif . Pengaruhnya antara lain:

a. Pekerjaan Pembesian dengan mesin dapat menghemat biaya dan waktu pelaksanaan.

b. Pelat Halfslab wiremesh dapat menghemat biaya, waktu serta hasil akhir yang lebih baik.

2. Metode pelaksanaan yang dipilih dari hasil analisis rekayasa nilai adalah :

a. Pelaksanaan pekerjaan pembesian yang semula menggunakan metode manual konvensional, diganti dengan metode manual dengan mesin karena dapat menghemat biaya dan mempercepat waktu pelaksanaan 
b. Pelaksanaan pekerjaan pelat yang semual menggunakan pelat konvensional, diganti dengan pelat halfslab wiremesh karena dapat menghemat biaya dan mempermudah serta mempercepat waktu pelaksanaan proyek

3. Penghematan biaya dan waktu yang diperoleh dari penerapan rekayasa nilai pada pekerjaan struktur adalah :

a. Pelaksanaan pekerjaan pembesian manual dengan mesin, didapatkan penghematan Rp. 171.114.467.

b. Pelaksanaan pekerjaan pelat halfslab tulangan wiremesh, didapatkan penghematan Rp. 308.213 .919

Setelah dilakukan analisa rekayasa nilai didapatkan penghematan potensial sebesar Rp. 479.328.386 Sedangkan untuk waktu pelaksanaan dapat dihemat selama 11 hari.

\section{SARAN}

1. Apabila dalam suatu proyek diperlukan analisa rekayasa nilai, sebaiknya analisa tersebut dilakukan pada akhir tahap perencanaan sampai pada awal pelaksanaan sehingga didapatkan penghematan potensial yang optimum tanpa mengurangi mutu proyek.

2. Metode pelaksanaan alternatif diperbanyak lagi dengan cara mengikuti perkembangan metode-metode pelaksanaan yang lebih menguntungkan.

3. Rekayasa Nilai tidak hanya dapat dilakukan pada metode pelaksanaan saja. Akan tetapi Rekayasa Nilai juga bisa dilakukan dengan cara lain misalnya : mengganti bahan, mengganti unit-unit precast, dll.

\section{DAFTAR PUSTAKA}

Barrie, Donald S. \& Boyd C. Paulson Jr. 1984. Manajemen Konstruksi Profesional - Edisi kedua. Alih Bahasa Sudinarto. 1990. Edisi Kedua. Jakarta : Erlangga

D. Miles, Lawrence. 1961. Techniques of Value Analysis and Engineering 1st Editon. USA : Lawrence D. Miles Value Foundation

Dell'Isola, Alphonse J. 1974. Value Engineering in the Construction Industry. New York : Construction Pub. Co

Departemen Pekerjaan Umum. 1991. Tata Cara Perhitungan Struktur Beton untuk Bangunan Gedung "SK SNI T-15-1991-03” Bandung : Yayasan Lembaga Penyelidikan Masalah Bangunan

Dipohusodo, Istimawan. 1996. Manajemen Proyek dan Konstruksi. Jogjakarta : Kanisius 
Ervianto, Wulfram L. 2006. Eksplorasi Teknologi dalam Proyek Konstruksi Beton Pracetak dan Bekisting. Yogyakarta : Andi.

Hidayat, Achmad Nurul dan Denny Ardianto. 2011. Rekayasa Nilai Pembangunan Gedung Rusunawa Ambarawa. Semarang : Universitas Diponegoro.

Hutabarat, J. 1995. Diktat Rekayasa Nilai (Value Engineering). Malang : Institut Teknologi Nasional.

Kementerian Pekerjaan Umum dan Perumahan Rakyat. 2016. Peraturan Menteri Pekerjaan Umum dan Perumahan Rakyat No, 28/M/2016 tentang analisa harga satuan pekerjaan. Jakarta : Kementerian Pekerjaan Umum.

Khakim, Zainul. 2011. Studi Pemilihan Pengerjaan Beton antara Pracetak dan Konvensional pada pelaksanaan gedung dengan metode AHP. Jurnal Rekayasa Sipil Universitas Brawijaya, Vol. 5, No. 2, hlm. 95-107.

Listono, Andi. 2011. Aplikasi Value Engineering terhadap struktur pelat dan balok pada proyek pembangunan Gedung Asrama Putra SMP MTA Gemolog. Surakarta : Universitas Sebelas Maret.

Soeharto, Iman. 1995. Manajemen Proyek : Dari Konseptual Sampai Operasional. Jakarta : Erlangga.

Suang, Lei. 1997. Penerapan Rekayasa Nilai Dalam Proses Penghematan Biaya Konstruksi. Medan : Universitas Sumatera Utara.

Sukma, Bima. 2011. Aplikasi Value Engineering Dengan Metode "Paired Comparison pada Struktur Pelat Beton. Depok : Universitas Indonesia.

Syahputra, M. Ryan. 2014. Penerapan Rekyasa Nilai Studi Kasus Proyek Pembangunan Kantor Perkebunan Medan. Medan : Universitas Sumatera Utara. 